\title{
Three perspectives on motivation and multicriteria assessment of organic food systems
}

\author{
$\underline{\text { Jeppe Lassøe }}^{1}$, Anders Kruse Ljungdalh $^{1}, \underline{\text { Hugo F. Alrøe }}^{2}, \underline{\text { Egon Noe }}^{2}$, Tove Christensen $^{3}$, Alex Dubgaard $^{3}$, Søren Bøve Olsen $^{3}, \underline{\text { Niels }}$ \\ Kargård $^{3}$ and Peter Kastberg $^{4}$
}

\begin{abstract}
Organic food systems are based on a complex of value criteria that often are not explicitly considered when agents think, communicate, and make decisions concerning organic food. Multicriteria assessment (MCA) refers to a group of tools that help the user to tackle such highly complex issues. The question is how an MCA tool should be designed to facilitate reflections, communication, and decision making in relation to organic food systems. A key issue is motivation. There are several divergent theories of motivation, and the question cannot be adequately answered by using any single theory. We discuss an economic, a psychosocial, and a relational perspective on motivation and MCA. Using the example of a consumer assessing and choosing products in the supermarket, the economic conception of motivation offers a focus on decision-making processes. The psychosocial approach to motivation draws attention to the influence of cognitive structures and experience-based emotional drivers. Finally, the relational approach stresses that motivation is situated in the relations between agents. We discuss how the three perspectives converge and diverge regarding the purpose of using an MCA tool, the scope of the MCA, the strategic focus, and challenges and potentials associated with an MCA tool. Through this multiple-perspective approach, the general idea of MCA is expanded and elaborated to refine the design of an MCA tool for organic food systems.
\end{abstract}

Key Words: motivation; multicriteria assessment (MCA); organic food

\section{INTRODUCTION}

Organic food systems are based on a complex of value criteria that are often not explicitly considered when consumers, retailers, producers, journalists, and other agents think, communicate, and make decisions concerning organic food. Eco-labels are widely applied as a means to boil the many aspects down to clearly identifiable symbols, offering agents a quick and simple way of coping with the complexity. However this strong reduction in complexity opens the door to misconceptions and distrust, and even when eco-labels are believed to be trustworthy, this trust can be threatened by changes in the public's mood and focus engendered by scandals and opposing messages. Because many value criteria are involved in such systems, a structured method to guide reflections, communication, and decision making is needed. It is therefore worth considering whether decisionmaking tools designed especially to handle complex issues might be applied to support agents considering issues relating to organic food.

Multicriteria assessment (MCA) refers to a range of methods developed to support decision making on such highly complex issues. For example, MCA is used by economists to help weigh up and assess complex issues as part of decision-making processes (Janssen 2001, Rauschmayer 2001). A variation on this method is social multicriteria evaluation, which makes a point of taking various agents' conflicting interests into account (Munda 2004). Developed partly as an alternative to monetary valuation methods such as cost-benefit analysis, these methods use information and communications technology to find new ways to handle complex issues. In essence, MCA is a tool that supports judgment by listing different options and making explicit how each of these options contribute to various criteria. MCA techniques usually provide a relative weighting system, although there are differences in how they combine data. However, unlike cost-benefit analysis, such techniques do not attempt to generate a final judgment by applying the same value unit to the measurement of each criterion and then summarizing the results.

Although MCA in principle seems to be a good idea, it also gives rise to critical questions about the weighting of different kinds of knowledge, the construction of indicators for each of the criteria, the complexity of MCA tools, and how to make these tools available and operational in practice to support reflection, communication, and decision making (Noe and Alrøe 2011). MCA is normally thought of as a decision-supporting tool for professionals in industry, policy, and planning. Can an MCA tool be designed for use by consumers, producers, and other agents when they are making choices regarding organic food?

This question lies at the core of MultiTrust, an interdisciplinary research and development project. During our collaboration we realized that disparate theories of motivation were in play. Each theory provides a certain perspective and reveals certain aspects of the role of motivation in relation to MCA, but the question cannot be adequately answered by using any single theory. Nor is it possible to unify the theories and their ontologies to create some kind of joint conceptualization. However, by taking a multiperspective approach that uses different perspectives in parallel (see Thorsøe et al. 2014), we were able to achieve a broader understanding that could aid development of a MCA tool for the complexity of organic food systems.

In this article we examine three perspectives on motivation as they relate to design of an MCA tool for organic food: economic, psychosocial, and relational. In doing so, we expose a number of important issues regarding the challenge of motivating people to use MCA for organic food issues. Moreover, we show how the perspective on motivation becomes expanded from an economic focus on product preferences to include users' psychosocial experiences and the relations and negotiations between agents.

${ }^{1}$ Department of Education, Aarhus University, Denmark, ${ }^{2}$ Department of Agroecology, Aarhus University, Denmark, ${ }^{3}$ Institute of Food and Resource Economics, University of Copenhagen, Denmark, ${ }^{4}$ Department of Business Communication, Aarhus University, Denmark 
It obviously matters whether the users of the organic food MCA tool are policy agents, producers, retailers, journalists, or consumers. Such a tool should be adaptable to each type of agent. However, in this article we chose to focus on consumers, partly because the idea of supplementing eco-labels with an organic food MCA tool is primarily targeted at consumers and partly because the challenge of motivating lay people, rather than professional agents, to use MCA is probably greater and thus better to help identify challenges that such an MCA tool needs to address.

We present the economic, psychosocial, and relational perspectives on motivation. In each case, we refer to the same imagined example of a consumer who is offered MCA support in a supermarket. We discuss issues and challenges associated with the three perspectives and conclude by showing potential contributions of the three different perspectives by using them in combination to help design an organic food MCA tool.

\section{THE CONCEPT OF MOTIVATION AND THREE DIFFERENT APPROACHES}

Particularly within psychology, the literature is replete with discussions of motivation. In a literature review, Kleinginna and Kleinginna (1981) discuss definitions referring to internal mechanisms, i.e., physiological and phenomenological definitions; functional processes, i.e., energizing, directing, and vector definitions; definitions restricting the scope of motivation, i.e., temporal restriction and definitions distinguishing motivation from other psychological processes; and comprehensive definitions, i.e., broad/balanced definitions and all-inclusive definitions suggesting that motivation is the cause of all behavior. According to the authors, the challenge is to restrict the use of the term to measurable functions and to avoid confusing the term with other overlapping concepts such as emotion and learning (Kleinginna and Kleinginna 1981). Although they recognize motivation as a source of change, they exclude definitions emphasizing social context as the site of motive construction. However, because our article covers various social aspects, we linked the concept of motivation to the theoretical domain of the human and social sciences.

Another key issue related to motivation and change is the relationship between cause and effect. This enables two fundamentally different approaches to motivation: as a subjective spring of action such as Aristotle's concept of appetite, triggering an action the outcome of which is satisfaction; or as the outcome of competent functioning (White 1959). According to White, living creatures do not explore their environments because they are in a state of deficit, but rather begin their explorative behavior when their basic needs have already been satisfied. This reverses the assumption that knowledge leads to motivation, which again leads to action. Instead, interaction with a complex environment leads to a growing sense of mastery, which then leads to motivation. Depending on whether motivation is understood as a trigger of action or as the result of competent functioning, it constitutes either the cause or the effect in a process of change.

The belief that motivation is the cause or effect of action has been challenged by $\mathrm{C}$. Wright Mills, who shifts the focus from motivation understood as subjective springs of action to motives, which are understood as socially constructed reasons attributed to ourselves and others (Mills 1940). The study object therefore becomes vocabularies of motive, i.e. the various reasons people provide for their actions in different situations (Mills 1940). In other words a person's behavior and possible behavioral change are functions of this person and his/her environment (Stern 2000).

\section{Motivation and the economic man}

In economic theory, consumers' needs and wants are seen as the motivation for their market behavior. It is a basic assumption that consumers' needs and wants are reflected in a set of preferences ordered in such a way that consumers will make rational choices between alternative bundles of consumer goods. This is known as the homo oeconomicus consumer, or the economic man conceptualization of human behavior. Rationality in this context means that consumers will choose a combination of consumer goods that will maximize their utility, i.e., satisfaction of preference, given the constraint represented by the available budget (Mas-Colell 1995). This consumer behavior model was extended by Lancaster (1966), who argued that consumers' demand is defined by the characteristics of a good, e.g., nutritional characteristics, taste, color, rather than the good as such. A good can also have public good characteristics, such as the perceived benefits to the environment of the absence of chemical pesticides in organic farming or perceived enhanced animal welfare. Public goods are characterized by one person's use not affecting another person's use of the good, i.e., nonrivalry, and the impossibility of excluding any individual from using the good, i.e., nonexcludability. Differences between organic and conventional food products are often presented as differences in specific characteristics. Therefore, the Lancasterian approach is often used in economic analyses of the demand for organic food products. It is a standard assumption that consumers know their own preferences, which in turn implies that they are able to identify the product combination that yields the highest possible utility from the available alternatives. Hence, if a consumer chooses an organic product, the motivation for such a choice is seen as rooted in the basic desire to maximize utility.

Another basic assumption concerning the economic man is that he is inherently self-interested and only concerned with maximizing his own utility. This implies that rational consumers will not feel incentives to pay individually for public goods such as reducing pollution because no one can exclude them from enjoying the good whether they choose to pay or not. This is the so-called free-rider problem (Simon 1957). A straightforward consequence of the free-rider problem is that public good characteristics of organic products, e.g., environmental benefits or enhanced animal welfare, would not affect consumers' demand and willingness to pay for organic products. Hence, in the traditional economic man conceptualization of human behavior, such public good characteristics are not expected to motivate consumers to buy more of the product, even though they have preferences for the public good characteristic. Instead, neoclassic economic theory suggests that a socially desirable provision of nonmarketed and public goods should be ensured through political decisions and public intervention.

\section{The economic view and MCA of organic food}

The utility maximization assumption can be used to explain why MCA is a relevant tool for consumers to use when deciding what to buy. Consumers are assumed to spend the time and effort required to identify the combination of goods that will maximize their utility. In line with the Lancasterian approach mentioned 
previously, this implies that for each good the consumer engages in an assessment of all relevant aspects that characterize the good for him or her. In other words, consumers are assumed to engage in an MCA.

However, a great deal of recent empirical research in marketing science and behavioral economics demonstrates that this assumption is violated more often than not. The more complex a good is, the greater the risk is that consumers do not engage in full MCA when considering whether to buy the good (see, e.g., Payne 1976, DeShazo and Fermo 2002). Consumers generally have constraints on the time and effort they allot to reaching a purchase decision. Although some consumers might spend a long time in the supermarket reflecting on what to put in the shopping basket, others rush along the aisles barely considering what they put in the basket. Both types of consumers might be motivated by utility maximization; they just have different preferences and thereby different trade-offs between time spent in the supermarket and time spent on other activities such as socializing with friends, playing with their kids, working an extra hour, and so forth. The utility gained from these alternative activities may contribute more to the overall utility experienced by an individual than what is lost by making "mistakes" in terms of nonoptimal choices in the supermarket, and as such, consumers' utility may still be maximized. A possible strategy for a consumer who prefers not to spend much time in the supermarket is simply to choose the cheapest combination of each bundle of goods. The consequence is that this consumer will rarely put an organic product in the basket because organic products are typically more expensive than conventional products.

Of course, the two types of consumers outlined here represent extremes. Most consumers will be somewhere in between, with a great deal of heterogeneity among individuals. Considering the many aspects of organic food products, it is likely that a proportion of consumers will simply find it overwhelming and extremely difficult to make a full MCA of organic products. There is a growing literature within behavioral economics that finds that consumers may resort to a range of different coping strategies when faced with choices that are cognitively demanding (see, e.g., Swait and Adamowicz 2001, Hensher 2010). One common simplifying strategy is to ignore complex aspects of a choice situation; another is to use some heuristics-based rule of thumb, e.g., always choosing the cheap alternative regardless of its other characteristics. Both strategies would seem to reduce the likelihood of consumers engaging in full MCA when faced with a choice between conventional and organic food products in the supermarket.

The traditional economics discipline offers no clear predictions as to how one might encourage more consumers to engage in MCA when considering organic food products. However, it is clear from empirical findings in behavioral economics that reduction of complexity is a key issue for consumers; for example, in the supermarket an important challenge is to get consumers to engage in full MCA of organic products. Therefore, from an economic perspective, using an MCA tool must be as simple and convenient as possible.

\section{Motivation as psychosocial dynamics}

Psychology should not be regarded as one uniform discipline but rather as a discipline with several, in many respects opposing, theoretical approaches. Among these, it is possible to find several more or less explicit theories on motivation (Kleinginna and Kleinginna 1981, Reber 1985, Ryan and Deci 2000, Schnack 2002). We do not conceive of motivation as a singular cause behind specific behaviors but as a combination of drivers behind our actions. These dynamics are not purely psychological; rather, they are tensions between the psychological structures generated through the individual's life story on the one hand and the present sociocultural context on the other hand (Illeris 1978). They are generated and embedded in the complex, and often conflictual, psychology of the individual as well as in the complex social interaction around social and material practices. Although this approach emphasizes the relation between individual and context as crucial for understanding motivation, it still operates with a subject as a carrier of orientations, values, experiences, and coping strategies that are dynamic parts of the motivational structure in the sense that they merge into one motive in some situations and create inner tensions, i.e., dissonances, driving the person either to act to overcome the dissonance or to repress some of the impulses to maintain existing beliefs or practices in other situations (Festinger 1957). In this sense, motivations are not the same as biological/bodily needs. Such needs are parts of the motivational dynamic but are always elaborated and transformed by the social practices and experiences of individuals throughout their life history. Obvious examples are our biological needs for food and sex, which are always elaborated through social experiences in the individual's life but which can never be fully understood by looking at the present relationship between the individual and his or her sociocultural context (Illeris 1978). It is important to note that when motivation is defined as a combination of drivers of action, impeding, and thus demotivating, factors should be included in the exploration of motivational structures.

\section{The psychosocial view and MCA of organic food}

This approach considers consumers as carriers of already generated orientations, values, experiences, and coping strategies that will be impeded or activated by what they meet in the social context, e.g., by entering a supermarket. Motivating the consumer to spend time reflecting on the values of organic food products, and to use MCA to decide what to buy, is basically seen as a matter of recognizing and responding to these psychosocial dynamics either by appealing to desires or by trying to dissolve mental barriers. Based on a review of research literature covering the fields of cognitive psychology, psychodynamic psychology, microsociology, and educational studies (Læssøe et al. 2011), we can illustrate how this approach might offer insight into what motivates and demotivates consumers to apply MCA to organic food.

When we as consumers are going to buy food in the supermarket, it is part of our everyday life with its gradually generated time structures, orientations, desires, ambivalences, and selfmanagement practices. Short factual information is not necessarily the best way to catch the consumer's awareness and motivate him or her to reflect on what to buy. For those who are already engaged green consumers, such a scientific, factual approach might be appealing (Læssøe et al. 1995). However, for others it might be better to relate to the dynamics of their everyday life and offer something that gently challenges and inspires them to assess and act differently (Berlyne 1960). Therefore, MCA in 
the supermarket should not be a tool telling the consumer "the right answers" but should, in a constructive manner, provide a framework for the consumer to reflect on organic food choices as part of his or her complex everyday life situation and the related dilemmas and questions.

The challenge is that issues associated with organic food are complex and relate to unpleasant and abstract risks as well as to values that may be perceived as ideologically controversial. In general, the abstract, invisible, and complex character of environmental risks impedes motivation for action. To cope with this, the MCA support should address not only the objective, scientifically documented risks. Consumers' motivation also can be enhanced by addressing the typical ways we as human beings perceive, assess, and cope with risks (Slovic 2000, Breck 2001). For example, who is responsible? Who is affected? Is it possible to control and escape? Is it deadly or not? The social aspects of risks, e.g., trust and credibility, are likewise important for consumers when they assess a risk (Breck 2001).

Another obstacle in motivating the consumer to spend time on an MCA is the very thing that MCA is intended to address: the complexity of the issue. Reducing the complexity by means of a quick visual overview seems essential. The MCA facility should furthermore rouse the consumers' curiosity and inspire them to gradually learn and include more aspects in their assessments before making their decision.

From a cognitive point of view, we know that information is always filtered and interpreted through already established mental models. The influence of these basic beliefs, orientations, and heuristics, i.e., coping strategies, on how the message is interpreted is stronger than the message's influence on existing beliefs and orientations (Spanheimer 1977, Dunwoody 2007, Moser and Dilling 2007, Hulme 2009). Consumers in a supermarket encounter organic food products with their own pre-established attitudes toward ecology and organic food, whether these are dominated by an economic rationality or a more ideological stance. From a psychosocial learning perspective, the best way to "unfreeze" conflicting attitudes and motivate new and deeper assessments is to apply a sensitive and open methodology; that is, to abstain from trying to convince consumers of the right things to do, but rather to ask questions and raise dilemmas, as well as to challenge and inspire in ways that neither affirm existing dominant norms nor attack the identity and practice of consumers to a degree to which they defend themselves by refusing any further reflection. The level in between these poles is often described as the practicable difference.

Finally, a very important recommendation from a psychosocial point of view is to acknowledge that it is not only the organic food systems but also the consumers' psychology and everyday lives that are complex. Attempts to motivate consumers to make use of MCA of organic food products will probably fail if they do not allow consumers to relate the MCA to their own concrete lifeworld. Here it is crucial to understand that our lifeworlds are not just a fixed set of routines but also include an ongoing negotiation of ambivalences. It has often been described as a paradox that consumers do not act according to their environmental consciousness. However, ambivalences are normal, and if people act completely inflexibly with no regard for the social context, it is this inflexible behavior that should be regarded as a psychopathological extreme (Leggewie and Weltzer 2009). Therefore, making an MCA tool attractive to consumers involves making it interactive; it should allow them to incorporate into the MCA the questions and concerns that originate from their own concrete lifeworld, with all its ambivalences and different ways of coping, i.e., self-practices.

\section{A relational approach to motivation}

We also analyzed motivation from a relational perspective based on semiotics (Peirce 1992, Nöth 2011) and relational metaphysics (Oliver 1981, Pirsig 1999). Motivation can be seen as a certain way of looking at values that focuses on values as the cause of action. That is, motivation is about how value relations lead to actions. However, in a relational perspective, values are relational, belonging neither to the subject nor to the object (Pirsig 1999, see also Thorsøe et al. 2014 in this Special Feature). Value relations are primary entities that constitute secondary entities such as objects and subjects. Because motivation is a certain way of talking about value relations as causes of action, the relational perspective also provides a relational view of motivation, which deviates from the more common approaches to motivation. Motivation is often placed in the object. One can speak of someone being motivated by somebody or something, and of motivating and demotivating events. A contrary approach is to place motivation with the subject. One can speak of agents and their motivation to act. Relational approaches to motivation focus on social interactions; that is, how motivating relations are created and how they are influenced by communication, dialogue, negotiation, knowledge, structural conditions, and so forth.

\section{The relational view of motivation and MCA: choice and change in organic food systems}

The relational character of motivation is for instance quite prominent in community-supported agriculture such as the French association pour le maintien d'une agriculture paysanne (AMAP) projects (Noe and Alrøe 2011). In these cases, what motivates consumers to buy and producers to produce has to do with the close relations between the consumers, who are actually more than consumers here, and food production, and between the producers and the processing, sale, and consumption of their produce.

If we look at how MCA might influence motivation in the case of consumers' choice of whether or not to purchase organic food in the supermarket, it is clear that MCAs should not be undertaken for the sole purpose of increasing expert knowledge so that more informative labeling can be provided, placing motivation in the product; or solely to influence the attitudes of consumers by trying to show that organic is better, placing motivation in the consumer. The role of such assessments must be to influence the relations that make consumers organic consumers and the system an organic food system. Therefore, MCA is first and foremost a communicational tool, and the relational perspective places certain demands with regard to how MCAs should be constructed and performed.

In the supermarket example, at least three distinct kinds of buying relations can be identified, which have led to differentiation between different sections within supermarkets and between specialized stores and shops. The three types of buying relations can be characterized by their focus, respectively, on price, i.e., discount products; aesthetics, i.e., taste, delicacies; and ethics, i. 
e., certified labels such as fair trade, organic, and so forth. In some cases the three types of relations are mixed, but here we look only at the distinct cases for the sake of clarity.

If we want to use MCA to influence consumer choices, the relational perspective points out that we need to take this differentiation of consumer buying relations into account. MCA is directly relevant to ethical buying relations, which are based on the communication of additional, ethically based considerations that have been used in the production process. Because of the complexity of more comprehensive MCAs, such processes are not unproblematic, and trust plays a major role in reducing the complexity of relations. On the other hand, MCA is only indirectly relevant to the price-oriented relations through the possible effect on the basic food regulations and standards, because additional considerations are visible only as higher price in this type of buying relation. Similarly, MCA is only indirectly relevant to the aesthetic buying relations because aesthetic buying relations are guided by taste and not by rational consideration.

\section{DISCUSSION}

We identified both converging and diverging interpretations of these three perspectives. They relate to the basic purpose of MCA, to the scope of the idea of using MCA, to the strategic focus, and to the observation of key challenges as well as potentials.

\section{Purpose}

There is divergence regarding the purpose of involving consumers in MCA. What are consumers being motivated to do? The economic answer is that MCA appeals to the consumers' utilitymaximizing motive and if an MCA tool can make it easier for consumers to make utility-maximizing decisions, their motivation might be strong enough to prefer to use the MCA compared with preferences for other activities. In the psychosocial perspective, the motivation for, and purpose of, using an MCA tool on organic food systems is instead to make it possible for consumers to expose and reflect on their own historically generated psychological dynamics, as well as dynamics related to their everyday life. In this approach, MCA becomes a tool for reflexive learning, during which the ecological and societal criteria are negotiated with issues from the personal lifeworld. In the relational view, motivation is created through communication; therefore, MCA becomes a tool to facilitate communication among agents about organic food systems. Furthermore, this approach stresses that the purpose is to develop ethics as social constructs.

In spite of these diverging objectives, it is possible to identify a potential way for the economic and psychosocial approaches to complement one another. Although neoclassical economic theory assumes that consumers choose between products in accordance with their preferences, the psychosocial approach expands on these drivers by looking at the whole complex of inner and everyday-life tensions. A central meeting point between these two approaches is the focus on coping strategies: both highlight such strategies in relation to motivation and design of MCA tools for consumers.

\section{Scope}

The three motivational approaches have different scopes for analyzing motivation in relation to organic food systems. The economic view has, in one sense, a broader scope than the others because it looks at consumer preferences and assessments of different products in general. On the other hand, the scope is narrow in the sense that the economic view explains motivation as a momentary individual phenomenon, whereas the psychosocial view includes both historical and social lifeworld perspectives, and the relational view further broadens the scope by focusing on communication and relations between different societal agents.

\section{Strategic focus}

The three approaches ascribe different weights to MCA as a decision-making and a communicative tool. In fact, concerning consumer motivation for using MCA, there are three tools to choose from rather than one. From an economic perspective, the strategic focus is on the MCA tool as a means to support the consumer in making utility-maximizing choices between products. This understanding is not absent in the psychosocial and relational views, but these approaches have a much stronger focus on communication. Within these approaches, an MCA tool becomes a tool for interactivity. In the psychosocial approach, this interactivity should enable the consumer to bring his or her own experiences, mental frames, and everyday life self-regulatory strategies into dialogue with general organic food criteria to reflect on and clarify his or her decisions. In the relational approach, the emphasis on the interactive qualities of the MCA tool stresses supporting communication and reflective dialogue between consumers and other agents.

\section{Key challenges}

The economic and the psychosocial views both identify individual coping strategies as key challenges when trying to motivate consumers to apply MCA to organic food systems. Compared with this, the concern of the relational view is how to motivate through creating relations in partnerships and chains. In other parts of our interdisciplinary work, trust and credibility have been addressed as key factors influencing whether consumers might apply MCA to organic food systems (I. Rittenhofer and K. Povlsen Klitgaard, unpublished manuscript). We might describe trust and credibility as social coping strategies that also can be included as a key challenge.

\section{Potentials}

The economic and psychosocial views both recommend that an MCA tool should be designed to reduce complexity, so that consumers will be motivated to apply it. However, the psychosocial view is somewhat hesitating in this regard because this might counteract the intention of facilitating consumers' learning to cope with organic food system choices at higher levels of complexity. In this view, the key might be to motivate consumers to apply MCA by offering them a simple overview as a gateway to further exploration of the different aspects of complex issues. Seen from the relational point of view, the MCA tool can potentially be transformed into a tool for communication and ethical reflections among consumers and other agents related to the organic food systems.

\section{Perspectives for MCA tool development}

The three approaches have served as theoretical inputs informing the development of a prototype of an MCA tool for organic food. In combination with inputs from a workshop with potential users, this has resulted in a set of design criteria stressing the importance of such a tool being: 
- easy to use in decision-making situations (see the economic perspective);

- useful for gaining a quick overview (see the economic and psychosocial perspectives);

- helpful with regard to getting in touch with other agents in the value chain (see the relational perspective) and with illustrating differing motives; and

- supportive of the user's own efforts to relate to, analyze, and optimize his or her own practices as part of the value chain (see primarily the psychosocial perspective, but also the other two perspectives).

Following these criteria, the tool will be developed to allow the different users in the chain to choose and weight the criteria that they use in their practices. By using visualizations, the entire value chain and the assessments of other stakeholders will be made transparent. It is, of course, a vital question whether the MCA tool can be made sufficiently simple and attractive so that it becomes useful and makes sense to consumers in a supermarket situation. This is a matter for empirical trial and evaluation. However, not least because of the theoretical input on motivation, the MCA tool seems to be quite different from ordinary MCA decision-making tools.

\section{CONCLUSION}

The complexity of values related to organic food systems is normally difficult to ascertain, understand, and act on for both producers and consumers, as well as for other agents. We suggest MCA as a method that may help in coping with this complexity. Because it is important to address the challenge of motivation when designing an MCA tool, we applied three fundamentally different perspectives on motivation: economic, psychosocial, and relational. By incorporating all three within a multiperspective approach, we were able to explore more aspects of motivation that are relevant when designing an MCA tool to help consumers when dealing with organic food issues. From an economic perspective, motivation is closely related to the buying situation and consumers' need to choose between products. This stresses the importance of gaining a quick overview and of support in assessing the options. From a psychosocial perspective, the key point is to design the tool in a way that makes it possible for the consumer to include his or her experiences and specific lifeworld strategies in the assessment process. This highlights the importance of an MCA tool that enables users to influence and change criteria and values in decision-making and reflexive processes. Finally, from a relational perspective, motivation is a matter of social interaction, and the tool should therefore be designed to allow dialogue between the agents involved in the value chain of the organic food system. Applying the three perspectives on motivation to the issue has proven the value of a multiple-perspective approach and provided input that aids development of a prototype MCA tool for agents participating in the organic food system.
Responses to this article can be read online at: http://www.ecologyandsociety.org/issues/responses. php/6397

\section{Acknowledgments:}

This article was written as part of the project Multicriteria Assessment and Communication of Effects of Organic Food Systems (MultiTrust), funded by The Danish Ministry of Food, Agriculture and Fisheries, Organic RDD 1 programme.

\section{LITERATURE CITED}

Alrøe, H. F., and E. Noe. 2011. A cross-disciplinary approach to multicriteria assessment and communication of the effects of organic food systems. Pages 313-316 in Proceedings of the Third Scientific Conference of ISOFAR. Volume 2. International Society of Organic Agriculture Research, Bonn, Germany.

Berlyne, D. E. 1960. Conflict, arousal, and curiosity. McGraw-Hill, New York, New York, USA.http://dx.doi.org/10.1037/11164-000

Breck, T. 2001. Dialog om det usikre [Dialogue about the uncertain]. Akademisk Forlag, Copenhagen. Denmark.

DeShazo, J. R., and G. Fermo. 2002. Designing choice sets for stated preference methods: the effects of complexity on choice consistency. Journal of Environmental Economics and Management 44(1):123-143. http://dx.doi.org/10.1006/jeem.2001.1199

Dunwoody, S. 2007. The challenge of trying to make a difference using media messages. Pages 89-104 in S. C. Moser and L. Dilling, editors. Creating a climate for change. Cambridge University Press, Cambridge, UK. http://dx.doi.org/10.1017/CBO9780511535871.008

Festinger, L. 1957. A theory of cognitive dissonance. Stanford University Press, Stanford, California, USA.

Hensher, D. A. 2010. Attribute processing, heuristics and preference construction in choice analysis. Pages 35-70 in S. Hess and A. Daly, editors. Choice modelling: the state-of-the-art and state-of-practice. Proceedings from the inaugural international choice modelling conference. Emerald Group Publishing, Bingley, UK.

Hulme, M. 2009. Why we disagree about climate change. Cambridge University Press, Cambridge, UK.

Illeris, K. 1978. Motivation i skolen [Motivation in the school]. Munksgaard, Copenhagen, Denmark.

Janssen, R. 2001. On the use of multi-criteria analysis in environmental impact assessment in The Netherlands. Journal of Multi-Criteria Decision Analysis 10(2):101-109. http://dx.doi. org/10.1002/mcda.293

Kleinginna, P., and A. Kleinginna. 1981. A categorized list of motivation definitions, with a suggestion for a consensual definition. Motivation and Emotion 5(3):263-291. http://dx.doi. org/10.1007/BF00993889

Lancaster, K. J. 1966. A new approach to consumer theory. Journal of Political Economy 74(2):132-157. http://dx.doi. org/10.1086/259131 
Leggewie, C., and H. Welzer. 2009. Das ende der Welt, wie wir sie kannten. S. Fischer, Frankfurt, Germany.

Læssøe, J., S. Breiting, A. K. Ljungdalh, and K. E. Nielsen. 2011. Håndtering af kompleks information. Afrapportering af MultiTrust task 2.3. Institut for Uddannelse og Pædagogik, Aarhus Universitet, Campus Emdrup, Denmark. online [URL]: http://orgprints.org/19936/2/19936.pdf

Læssøe, J., F. Hansen, and M. S. Jørgensen. 1995. Grønne familier - miljøvenlige levemåder - og mulighederne for at støtte udviklingen af dem. Danmarks Tekniske Universitet, Kongens Lyngby, Denmark.

Mas-Colell, A. 1995. Microeconomic theory. Oxford University Press, Oxford, UK.

Mills, C. W. 1940. Situated actions and vocabularies of motive. American Sociological Review 5(6):904-913. http://dx.doi. org/10.2307/2084524

Moser, S. C., and L. Dilling, editors. 2007. Creating a climate for change. Cambridge University Press, Cambridge, UK. http://dx. doi.org/10.1017/CBO9780511535871

Munda, G. 2004. Social multi-criteria evaluation: methodological foundations and operational consequences. European Journal of Operational Research 158(3):662-677. http://dx.doi.org/10.1016/ S0377-2217(03)00369-2

Noe, E., and H. F. Alrøe. 2011. Quality, coherence and cooperation: a framework for studying the mediation of qualities in food networks and collective marketing strategies. International Journal of the Sociology of Agriculture and Food 18(1):12-27.

Nöth, W. 2011. From representation to thirdness and representamen to medium: evolution of Peircean key terms and topics. Transactions of the Charles S. Peirce Society 47(4):445-481. http://dx.doi.org/10.2979/trancharpeirsoc.47.4.445

Oliver, H. H. 1981. A relational metaphysic. Studies in philosophy and religion. Volume 4. M. Nijhoff, The Hague, The Netherlands. http://dx.doi.org/10.1007/978-94-009-8250-5

Payne, J. W. 1976. Task complexity and contingent processing in decision making: an information search and protocol analysis. Organizational Behavior and Human Performance 16(2):366-387. http://dx.doi.org/10.1016/0030-5073(76)90022-2

Peirce, C. S. 1992. The essential Peirce: selected philosophical writings. Volume 1 (1867-1893). N. Houser and C. Kloesel, editors. Indiana University Press, Bloomington, Indiana, USA.

Pirsig, R. M. 1999. Objects, subjects, data and values. Pages 79-98 in D. Aerts, J. Broekaert, and E. Mathijs, editors. Einstein meets Magritte: an interdisciplinary reflection on science, nature, art, human action and society. The white book of "Einstein meets Magritte.” VUB University Press, Brussels, Belgium. http://dx. doi.org/10.1007/978-94-011-4704-0 5

Rauschmayer, F. 2001. Reflections on ethics and MCA in environmental decisions. Journal of Multi-Criteria Decision Analysis 10(2):65-74. http://dx.doi.org/10.1002/mcda.288

Reber, A. S. 1985. Dictionary of psychology. First edition. Penguin Books, London, UK.
Ryan, R. M., and E. L. Deci. 2000. Intrinsic and extrinsic motivations: classic definitions and new directions. Contemporary Educational Psychology 25(1):54-67. http://dx.doi.org/10.1006/ ceps. 1999.1020

Schnack, K., editor. 2002. Psykologisk opslagsbog. Christian Ejlers' Forlag, Copenhagen, Denmark.

Simon, H. 1957. Models of man: social and rational; mathematical essays on rational human behavior in society setting. Wiley, New York, New York, USA.

Slovic, P. 2000. The perception of risk. Routledge, London, UK.

Spanheimer, L. 1977. Kunsten at gøre sig forstået. Om kommunikationens psykologiske barrierer. Hans Reitzels Forlag, Copenhagen, Denmark.

Stern, P. C. 2000. New environmental theories: toward a coherent theory of environmentally significant behavior. Journal of Social Issues 56(3):407-424. http://dx.doi.org/10.1111/0022-4537.00175

Swait, J., and W. Adamowicz. 2001. The influence of task complexity on consumer choice: a latent class model of decision strategy switching. Journal of Consumer Research 28(1):135-148. http://dx.doi.org/10.1086/321952

Thorsøe, M. H., H. F. Alrøe, and E. Noe. 2014. Observing the observers: uncovering the role of values in research assessments of organic food systems. Ecology and Society 19(2): 46. http://dx. doi.org/10.5751/ES-06347-190246

White, R. 1959. Motivation reconsidered: the concept of competence. Psychological Review 66(5):297-333. http://dx.doi. org/10.1037/h0040934 